\title{
GIS-based Analysis of LS Factor under Coal Mining Subsidence Impacts in Sandy Region
}

\author{
W. Xiao ${ }^{1,2^{*}}$, H.-Y Zhang ${ }^{3}$ and J.-Y Zhang ${ }^{1}$ \\ ${ }^{1}$ Institute of Land Reclamation and Ecological Restoration, China University of Mining and Technology (Beijing), Beijing, 100083- China \\ ${ }^{2}$ State Key Laboratory of Coal Resources and Safe Mining, China University of Mining and Technology (Beijing), Beijing, 100083- China \\ ${ }^{3}$ Hunan Planning Institute of Land and Resources, Changsha, 410000-China
}

Received 13 June 2014; Accepted 15 September 2014

\begin{abstract}
Coal deposits in the adjacent regions of Shanxi, Shaanxi, and Inner Mongolia province (SSI) account for approximately two-thirds of coal in China; therefore, the SSI region has become the frontier of coal mining and its westward movement. Numerous adverse impacts to land and environment have arisen in these sandy, arid, and ecologically fragile areas. Underground coal mining activities cause land to subside and subsequent soil erosion, with slope length and slope steepness (LS) as the key influential factor. In this investigation, an SSI mining site was chosen as a case study area, and 1) the pre-mining LS factor was obtained using a digital elevation model (DEM) dataset; 2) a mining subsidence prediction was implemented with revised subsidence prediction factors; and 3) the post-mining LS factor was calculated by integrating the pre-mining DEM dataset and coal mining subsidence prediction data. The results revealed that the LS factor leads to some changes in the bottom of subsidence basin and considerable alterations at the basin's edges of basin. Moreover, the LS factor became larger in the steeper terrain under subsidence impacts. This integrated method could quantitatively analyse LS changes and spatial distribution under mining impacts, which will benefit and provide references for soil erosion evaluations in this region.
\end{abstract}

Keywords: Mining Area, Soil Erosion, LS Factor, USLE, GIS, Mining Subsidence, Sandy Region.

\section{Introduction}

Underground coal mining results in land subsidence [1] and numerous adverse environmental and social changes [2]. The negative impacts of coal mining, including coal waste occupation, digging of opencast pits, dumps, and ground subsidence, can lead to landslides, spontaneous combustions and explosion, and cracks [3][4]. In China, $92 \%$ of the coal comes from underground mining, which is a unique phenomenon among the world's coal mining countries [5]. In the US, Australia, India, and Indonesia, coal is mainly acquired via surface mining. In terms of subsidence, the effects are different in western and eastern China because of variations in geology and natural conditions. Mining subsidence induces farmland submergence in eastern China and leads to severe ecological disasters in western China. With the rapid development of coal exploitation, coal mining has been expanding westward. Therefore, the adjacent regions of Shanxi, Shaanxi, and Inner Mongolia province (SSI) became the frontier that accounts for approximately two-thirds of China's coal production, and it is now known as the "Black Triangle" or the "Black Gold Triangle." This area covers Shenmu and Fugu in Shaanxi province,

*E-mail address: xiaowuwx@126.com

ISSN: 1791-2377 @ 2014 Kavala Institute of Technology. All rights reserved.
Shuozhou in Shanxi Province, and Junger and Erdos in Inner Mongolia. This area has a relatively dry climate, low rainfall, and a fragile ecological environment. Underground coal mining alters the original topography, thus exacerbating soil erosion and vegetation degradation. The related adverse ecological and environmental issues include: 1) ground fissures, 2) terrain alternation, 3) soil erosion, and 4) vegetation degradation; thus, mining subsidence planning and environmental conservation are major concerns. The relationships between mining subsidence and related issues are shown in Figure 1. Mining subsidence-induced soil erosion is considered one of the most prominent problems in western China.

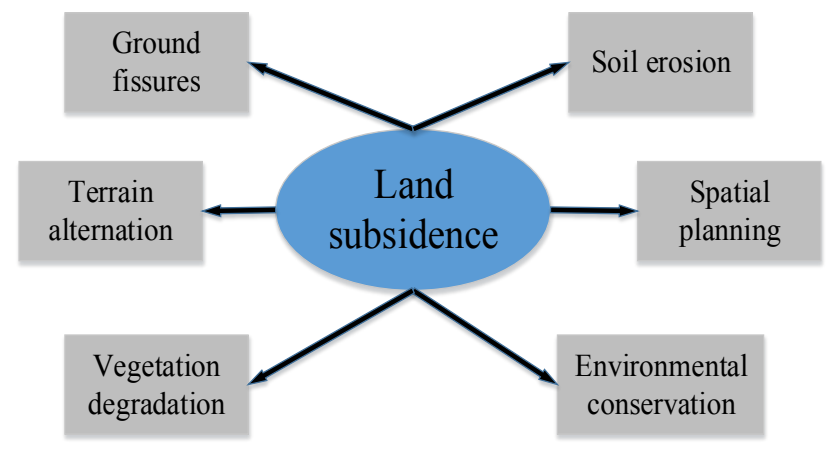

Fig. 1. The importance of land subsidence in drought coal mines 
Since the 1990s, growing concerns about environmental issues, and the implementation of Geographic Information System (GIS) technology and soil erosion assessment models, the Universal Soil Loss Equation (USLE) has been applied to soil erosion assessments and mapping on regional scales. In such applications, the most critical factor is LS (Slope Length and Slope Steepness), which is generated using the GIS platform. The LS factor is a parameter that gives a sense of topography characteristics set [6]. Most of the terrain factors such as slope, catchment area, slope, flat, can pixel and its surrounding elements like the three elevation data obtained from any one. The main factors involved in the secondary component are the combination of factors that describe spatial changes. Therefore, the LS factor is an important terrain factors that affects soil erosion. The spatial distribution and patterns of slope length, the impact of landforms on slope length, and the relationship between slope length and gradient are critical for soil erosion and research into this process. Many scholars have employed GIS platforms to study the LS factor (Remortel, 2001) [7]. Sui (2010) studied the LS factor acquisition method based on digital elevation model (DEM) and remote-sensing data [8], Qin (2010) discussed the effects of DEM data resolution changes on the value of LS [9]. Furthermore, Fistikoglu (2002) implemented a soil erosion study by using GIS and the USLE model [10], and some research was carried out regarding soil erosion prediction based on the LS factor [11]. However, the LS factor is dynamic during mining subsidence, and changes in this value can influence subsequent soil erosion. It is very important to obtain the dynamic LS factor and quantitatively analyze its effect on soil erosion and land disturbance. This paper proposes a methodology that includes pre-mining analysis, mining subsidence prediction, and post-mining analysis to quantitatively evaluate changes in LS and spatial distributions during mining processes. The proposed method provides a reference and foundation for soil erosion and loss caused by mining subsidence.

\section{Study Area}

This study investigated the Bulianta coal mine that was built and is managed by the Shenhua Coal Group. The Bulianta coal mine is located in Wulanmulun town, Erdos, Inner Mongolia (Figure 2). It is a typical sandy and arid mining area in western China, with barren soil and sparse ground vegetation. The natural elevation is 1,228-1,328 $\mathrm{m}$ above mean sea level, with an average of $1280 \mathrm{~m}$. The region is largely covered by Quaternary Aeolian sand and other loose layers. The pre-mining geomorphology is relatively flat, with higher elevation in the northwest, southeast, and central portions. The region has a typical temperate continental climate, with abundant sunshine, four distinct seasons, and a spatial and temporal distribution of precipitation with very little uneven evaporation. The annual precipitation in the region in 195 to $531 \mathrm{~mm}$ (average $357 \mathrm{~mm}$ ) and mostly falls between July and September.

The Bulianta mine is the largest underground mine in the world. It is located at Ordos Inner Mongolia with 106.43 $\mathrm{km} 2$ of mining area, $1,550 \mathrm{Mt}$ of mineable reserve, and 77 years of service life. The major coal seams are No. 1-2, 2-2, and 3-1. The total production reached $25 \mathrm{Mt}$ in 2010. The study area covered a portion of the coal mine: seven panels shown in Figure 3.
The main coal seams in this area are No. 1-2, with an average thickness of about $4.5 \mathrm{~m}$. Buried depths of coal seams are about $190-220 \mathrm{~m}$, and the dip angle of coal seams varies from $1^{\circ}$ to $3^{\circ}$. The overburden has a thin alluvial strata and a very thick bedrock reaching 180-200 m. The seven panels that include the No. 1-2 coal seam were first mined 2006 and are still affected by mining impacts. This study analyzed the dynamic evolution of ground condition, with a focus on LS factor changes due to coal mining subsidence.

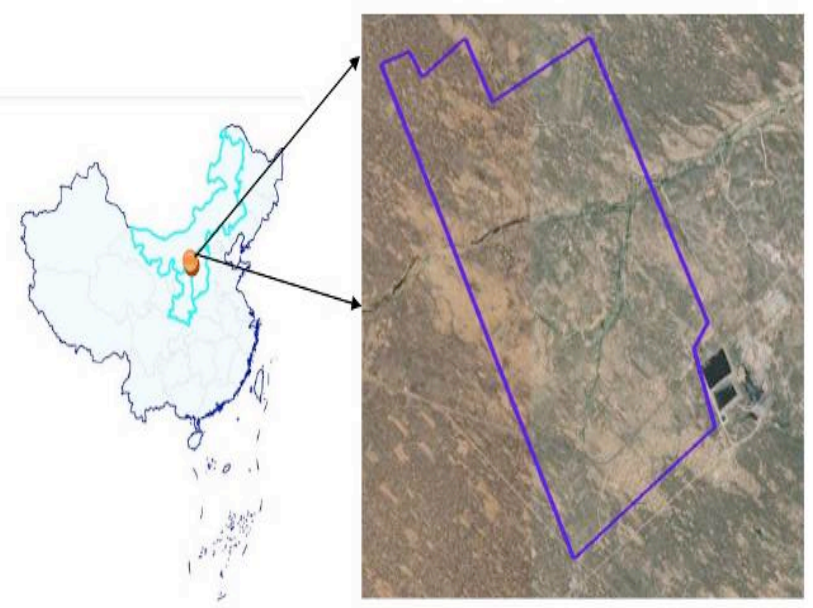

Fig. 2. The remote-sensing image showing the study area

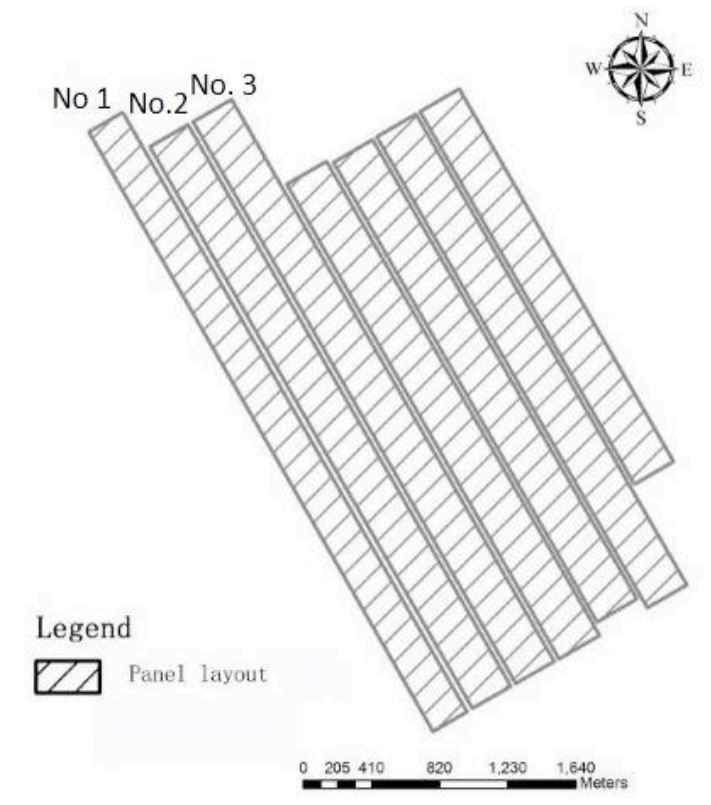

Fig. 3. Panel layout of the study area

\section{Material and Methods}

\subsection{Pre-mining LS factor}

As introduced in section 2, the study area was comprised of seven panels. The first (No. 1) was mined in 2007. A contour map (1:2,000 scale) was obtained in 2005 before mining activities were initiated. Under the GIS platform, Arcgis software designed by the Environmental Systems Research Institute (ESRI) was employed to analyze premining terrain conditions. The pre-mining DEM image was obtained using Kringer interpolation, which is shown in Figure 4. 
$\mathrm{L}$ is the slope length factor, representing the effect of slope length on erosion, while $\mathrm{S}$ is the slope steepness, representing the effect of slope steepness on erosion. The $\mathrm{L}$ and $\mathrm{S}$ factors are usually considered together to determine their combined effects on erosion. Generally, the LS factor represents the ratio of regional and standard region soil losses. Typically, the LS factor and soil erosion intensity is proportional, as are the acceleration factors of soil erosion. The equation proposed by Wischmeier and Smith [12] was adopted to analyze the LS factor, as shown below:

$$
\begin{aligned}
& \mathrm{L}=\left[\frac{\lambda}{22.13}\right]^{\mathrm{m}} \\
& m=\frac{F}{F+1} \\
& \mathrm{~F}=\frac{\sin \theta / 0.0896}{3(\sin \theta)^{0.8}+0.56}
\end{aligned}
$$

Where $\lambda$ represents slope length, 22.13 represents the slope length of standard region, $m$ represents the slope length indicator, and $\theta$ is the slope.

Due to a large number of theoretical and experimental study surfaces, in terms of soil erosion, the influence of unit catchment area was much bigger than the influence of $\lambda$ on the two-dimensional surface flow environment [13]. Therefore, in the process of solving the practical requirements, $\lambda$ was replaced by the calculation of the unit catchment area, which was calculated as follows:

$$
\begin{aligned}
& L=\frac{\left(A_{i j}+D^{2}\right)^{m+1}-A_{i j}^{m+1}}{x_{i j}^{m} \cdot D^{m+2} \cdot 22.13^{m}} \\
& x_{i j}=\cos \alpha_{i j}+\sin \alpha_{i j}
\end{aligned}
$$

Where $A_{i j}$ is the upstream catchment area of the current grid cell, D represents the interval of DEM grid, $x_{i j}$ is contour length factor, and $\alpha_{i j}$ is the aspect of the grid.

The equation proposed by McCool [14] and Liu [15] was adopted to calculate the $\mathrm{S}$ factor in relatively gentle and steep slope conditions, as shown below:

$$
\begin{aligned}
& S=10.8 \sin \theta+0.03 \quad 0^{\circ} \leq \theta<5^{\circ} \\
& S=16.8 \sin \theta-0.50 \quad 5^{\circ} \leq \theta<10^{\circ}
\end{aligned}
$$

$$
\mathrm{S}=21.91 \sin \theta-0.96 \quad \theta \geq 10^{\circ}
$$

Under the Arcgis platform utilizing hydrological analysis, spatial analysis, and grid-computing modules, the LS factor was extracted from DEM data (Figure 5).

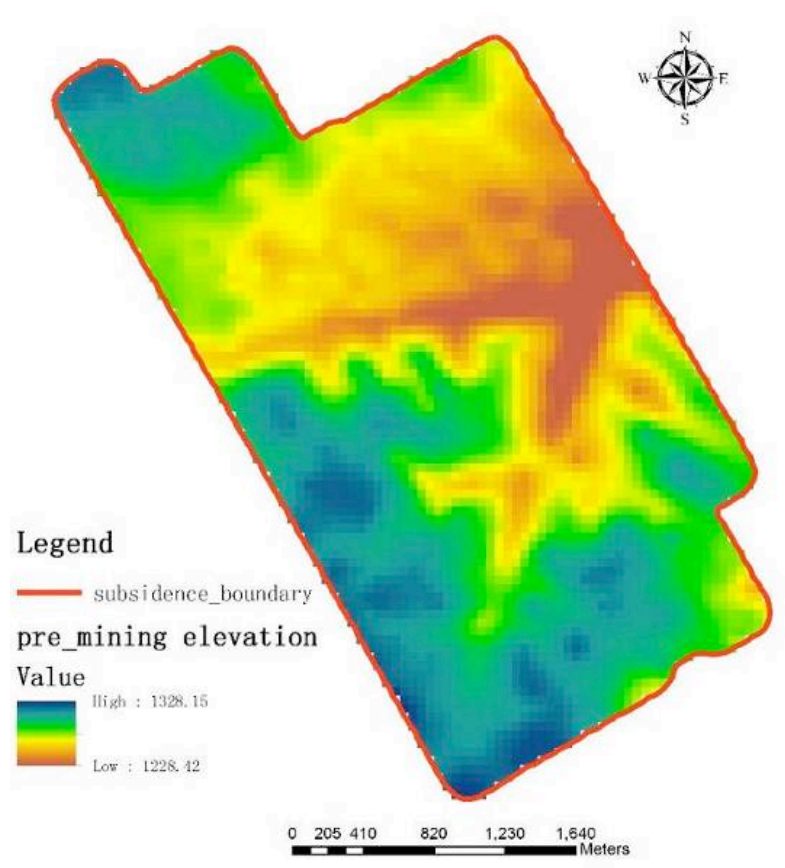

Fig. 4. Pre-mining DEM

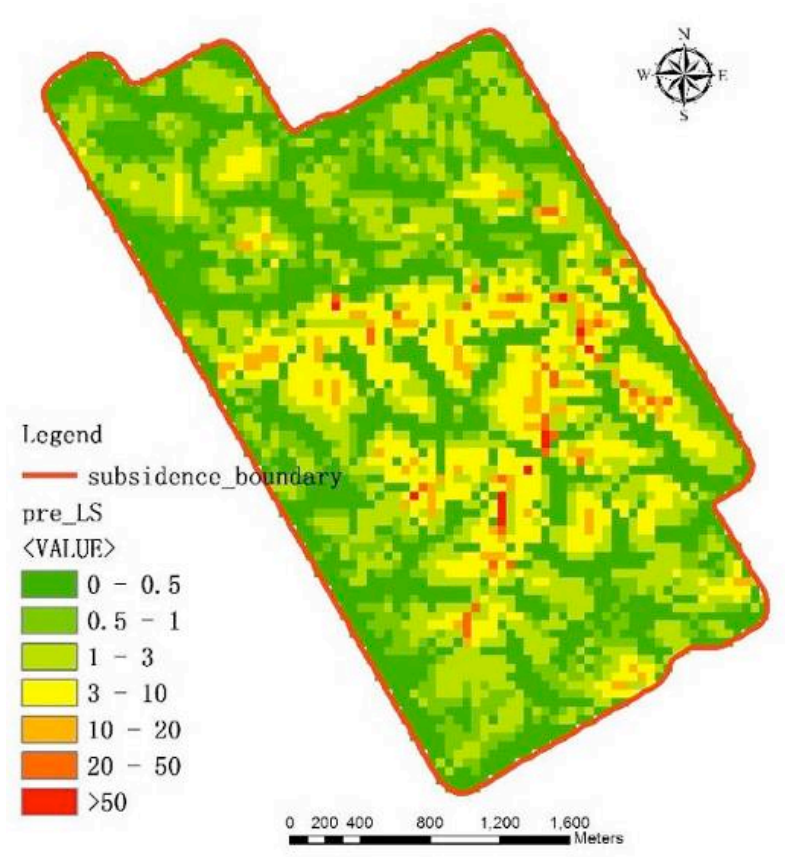

Fig. 5. Pre-mining LS factors

\subsection{Subsidence prediction analysis}

The probability integral method is based on random medium theory and is the most mature and widely used method in China. This method studies stratum movements by considering the rock mass as a random medium and the stratum movement as a random process obeying statistical rules. It allows accurate prediction for any shape and multiple work faces. For any single work face of any shape, the surface is first divided into many small rectangular faces along the $\mathrm{X}$ or $\mathrm{Y}$ direction. Secondly, the movements and deformation on the surface caused by every small rectangular face are calculated, and the results can display the movements and deformation in a specified direction at any point on ground. Thirdly, the prediction data caused by small rectangular faces are superimposed to determine the subsidence data for a single work face. A similar process is followed if there are many work faces in a specified area. 
The subsidence height caused by a rectangular work face is shown as follows:

$$
\begin{aligned}
& \mathrm{W}_{\mathrm{A}}(\mathrm{x}, \mathrm{y})=\mathrm{W}_{\max } \mathrm{C}_{\mathrm{x}} \mathrm{C}_{\mathrm{y}} \\
& \mathrm{W}_{\max }=\mathrm{mq} \cos \alpha \\
& \mathrm{C}_{\mathrm{x}}=\frac{1}{\sqrt{\pi}} \int_{\sqrt{\pi} \frac{\mathrm{x}-1}{\mathrm{r}}}^{\sqrt{\pi} \frac{\mathrm{x}}{\mathrm{r}}} \mathrm{e}^{-\lambda^{2}} \mathrm{~d} \lambda \\
& \mathrm{C}_{\mathrm{y}}=\frac{1}{\sqrt{\pi}} \int_{\sqrt{\pi} \frac{\mathrm{y}-\mathrm{L}}{\mathrm{r}_{2}}}^{\sqrt{\pi} \frac{\mathrm{y}}{\mathrm{r}_{1}}} \mathrm{e}^{-\lambda^{2}} \mathrm{~d} \lambda
\end{aligned}
$$

Where $\mathrm{W}_{\max }=$ maximum subsidence, $\mathrm{m}=$ seam thickness, $\mathrm{q}=$ subsidence factor, $\alpha=$ dip angle, $1=$ panel length along strike, $\mathrm{L}=$ panel width along $\operatorname{dip} ; \mathrm{r}=\frac{H}{\tan \beta}, \mathrm{r} 1=\frac{H_{1}}{\tan \beta}, \mathrm{r} 2=$ $\frac{\mathrm{H}_{2}}{\tan \beta}$, radius of the influence circle, $\tan \beta=$ tangent of draw angle, $\mathrm{H}=$ depth along strike, $\mathrm{H}_{1}=$ depth along the boundary of the rise side, and $\mathrm{H}_{2}=$ depth along the boundary of the dip side [16].

When prediction software is programmed according the above subsidence prediction model to generate mining subsidence data, the algorithm and prediction software has a very good performance history in China [1].

Using the probability integral method as a prediction model, the prediction parameters are shown in table 1 , and the predicted subsidence contours are depicted in Figure 6.

Table 1. Basic parameters for surface movement and deformation prediction

\begin{tabular}{c|c}
\hline Parameters & Value \\
\hline Coefficient of the initial mining & 0.55 \\
Horizontal movement coefficient & 0.26 \\
Influence propagation angle tangent & 2.51 \\
The displacement distance & $0.03 \mathrm{H}$ \\
Influence angle & $90-0.7 \alpha$ \\
\hline
\end{tabular}

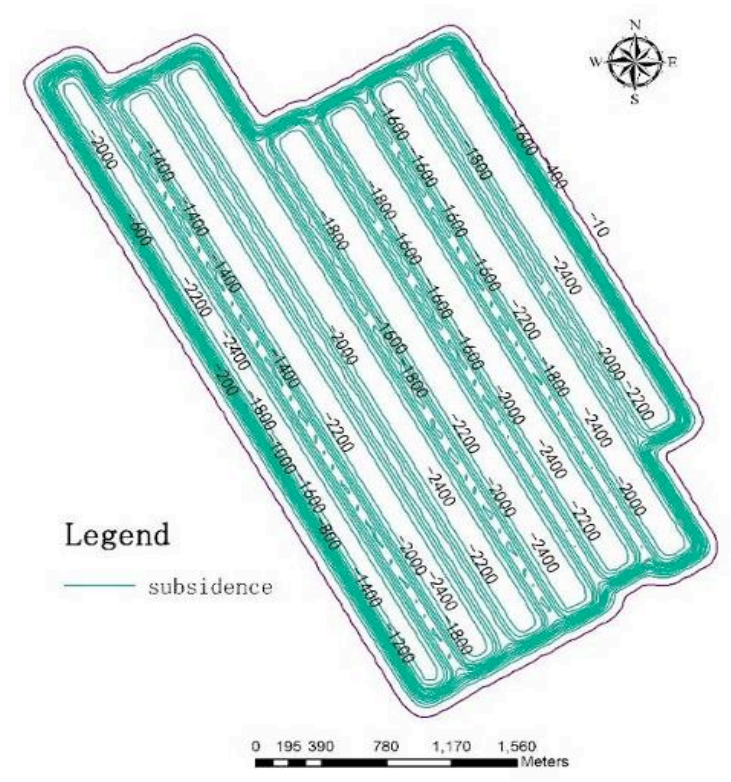

Fig. 6. Mining subsidence contours

\subsection{Post-mining LS factor}

The research was conducted to determine LS factor change laws under mining conditions; thus, mining subsidence prediction was implemented. By using GIS and coupling the predicted result of subsidence in different mining stages with the original elevation data, a dynamic visualization of mining processes is achieved that more clearly reflects geomorphologic features. Furthermore, it visually shows the variation and characterization of surface subsidence, according to which we can analyze and evaluate the degree of mining subsidence damage [16]. A post-mining DEM was generated and a post-mining LS factor map was subsequently obtained (Figure 7).

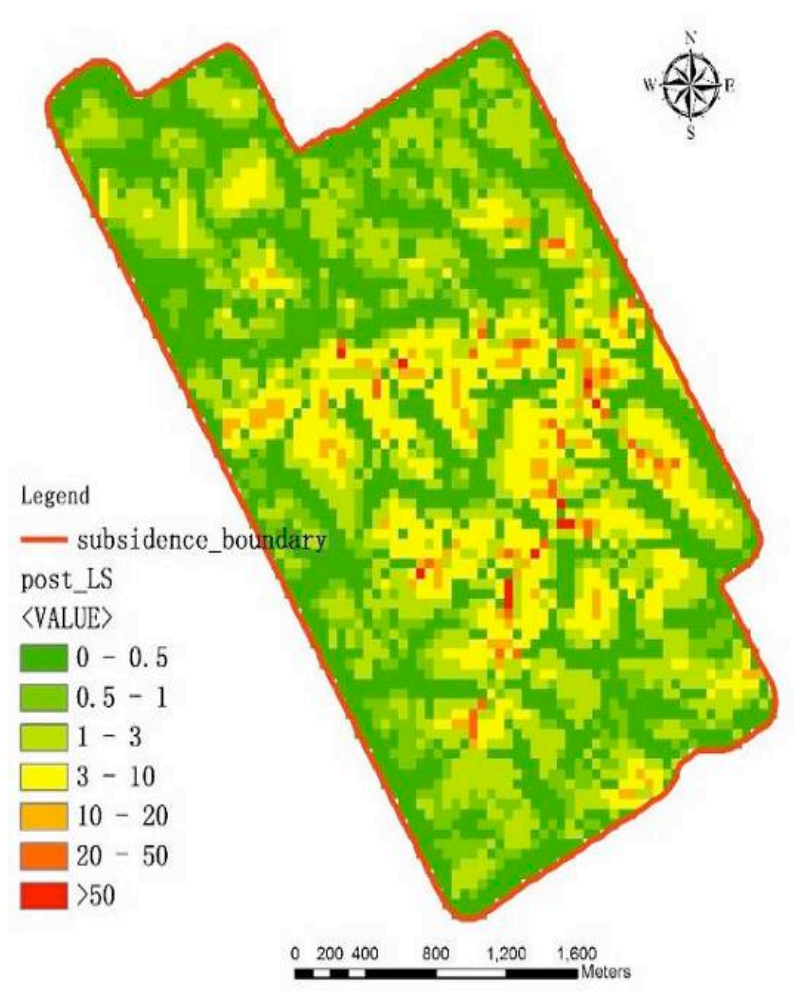

Fig. 7. Post-mining LS factors

\section{Result Analysis}

The LS factor, in reference to the USLE, and its influence on the estimation of water erosion with the use of hydrological models and GIS is quite important in mining area. With the help of mining subsidence prediction software, the potential LS changes between pre- and post-mining conditions can now be analyzed. At the same time, a new question arises. Researchers need to know how the LS factor changes over a given spatial distribution, to determine how to prevent soil erosion. By using the raster calculator provided by Arcgis software, one can obtain the LS difference of pre-mining and post-mining conditions (Figure 8). These changes are summarized in Table 2. 


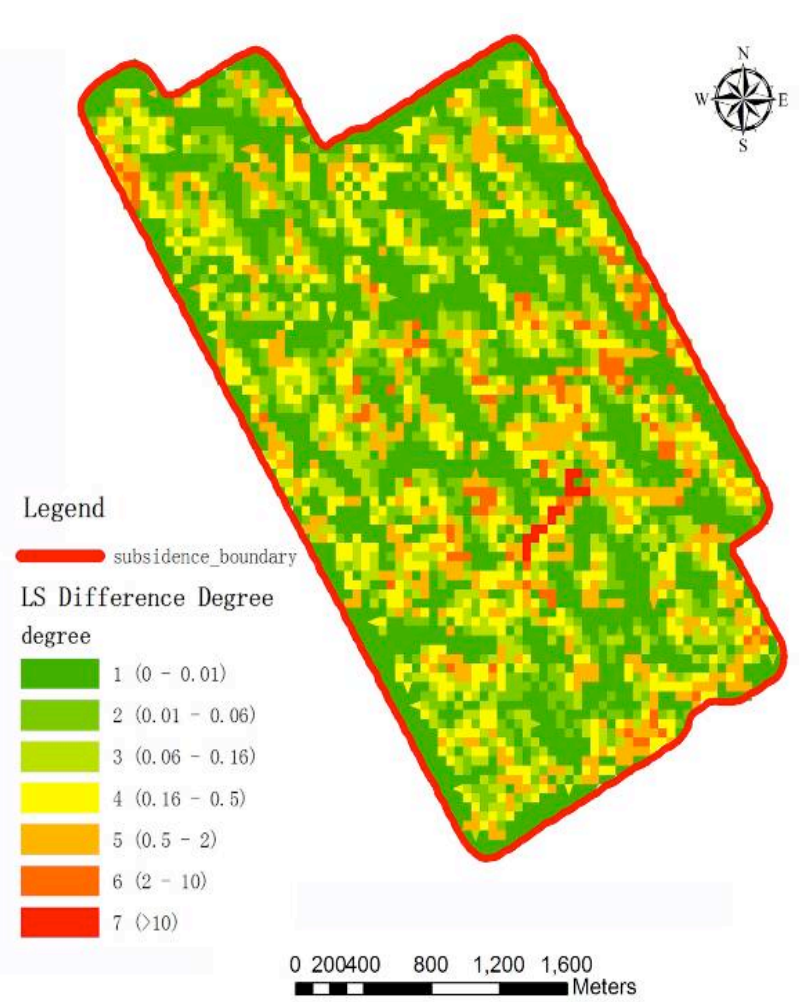

Fig. 8. Pre- and post-mining LS changes

Table 2. Pre- and post-mining LS changes

\begin{tabular}{c|c|c|c}
\hline Degree & Range & Sum area $\left.\mathbf{( h m}^{2}\right)$ & Percentage (\%) \\
\hline 1 & $0-0.01$ & 424.60 & 42.25 \\
2 & $0.01-0.06$ & 133.58 & 13.29 \\
3 & $0.06-0.16$ & 134.97 & 13.43 \\
4 & $0.16-0.50$ & 148.15 & 14.74 \\
5 & $0.50-2$ & 132.06 & 13.14 \\
6 & $2-10$ & 27.77 & 2.76 \\
7 & $>10$ & 3.75 & 0.37 \\
Total & - & $1,004.89$ & 100.00 \\
\hline
\end{tabular}

The LS factor increased in different levels, indicating that soil erosion may have accelerated due to the mining subsidence influence. LS changes was categorized into seven degrees, degrees 1 to 4 were gentle change, and the maximum value was 0.5 , whereas degrees 5 to 7 indicate severe change, with the maximum value reaching 10 or even more. Our results indicate that the LS factor changed dramatically in $16.28 \%$ of the study area, which is marked in red in Figure 8. The red distribution denotes steep slopes, suggesting that the hilly area would be more impacted by mining subsidence compared with relatively flat areas. Furthermore, most of the red color (or LS factor value increased area), was at the edges of the subsidence basin. Therefore, more attention should be paid to preventing soil erosion in those areas.

\section{Conclusions}

By employing of GIS and mining subsidence prediction software, the LS factor of Pre- and post-mining was obtained with spatial distribution in time domain. The pre-mining LS factor was obtained using a digital elevation model (DEM) dataset, and a mining subsidence prediction was implemented with revised subsidence prediction factors. Furthermore, the post-mining LS factor was calculated by integrating the pre-mining DEM dataset and coal mining subsidence prediction data. The results indicate that:

1) The hilly area would be more impacted by mining subsidence compared with relatively flat areas;

2) LS factor leads to some changes in the bottom of subsidence basin and considerable alterations at the basin's edges of basin.

The integrated method could quantitatively analyze LS changes and spatial distribution under mining impacts, which will benefit and provide references for soil erosion evaluations and related land reclamation work in this region.

\section{Acknowledgements}

The research was supported by Joint Funds of the National Natural Science Foundation of China with approval No. U1361203, and the State Key Laboratory for Coal Resources and Safe Mining, China University of Mining \&Technology, approval No. SKLCRSM12KFB07. We offer special thanks for the valuable research and assistance provided by Bulianta coal mine.

\section{References}

[1]. Xiao W., Hu Z.-Q., Zhang R.-W. and Zhao Y.-L., "A simulation of mining subsidence and its impacts to land in high ground water area- An integrated approach based on subsidence prediction and GIS", Disaster Advance, 6(S4), 2013, pp. 142148.

[2]. Hu Z.-Q., Wei Z.-Y. and Qin P., "Concept and methods for soil reconstruction in mined land reclamation", Soils, 37(1), 2005, pp. 8-12. (in Chinese)

[3]. Bi Z.-W. and Ding D.-X., "Surface damage caused underground mining and prevention", Safe Environment Engineering, 10, 2013, pp. 54-57. (in Chinese)

[4]. Gao Y.-F. and Jia J.-Y., "The attenuation function of surface subsidence and stability analysis of the subsidence area", Journal of China Coal Society, 34, 2009, pp. 892-896. (in Chinese)

[5]. Hu Z.-Q., Xu X.-L. and Zhao Y.-L., "Dynamic monitoring of the land subsidence in mining area from multisource remote-sensing data - a case study at Yanzhou, China", International Journal of Remote Sensing, 33, 2012, pp.5528-5545.
[6]. Desmet P. and Govers G., "A GIS procedure for automatically calculating the USLE LS factor on topographically complex landscape units", Journal of Soil and Water Conservation, 51(5), 1996, pp. 427-433.

[7]. Remortel V., Hamilton R. and Hickey R., "Estimating the LS factor for RUSLE through iterative slope length processing of digital elevation data", Cartography, 30(1), 2001, pp. 27-35.

[8]. Sui X. and Wang W.-F., "Extraction and analysis of terrain factors in USLE based on DEM", Engineering of surveying and Mapping, 19(5), 2010, pp. 20-23. (in Chinese)

[9]. Qin W., Zhu Q.-K. and Zhang Y., "Advance in researches on slop length factor in universal soil loss equation", Science of Soil and Water Conservation, 8(2), 2010, pp. 117-124. (in Chinese)

[10]. Fistikoglu O., Nilgun B. and Harmanciog L., "Integration of GIS with USLE in Assessment of Soil Erosion", Water Resources Management, 16, 2002, pp. 447-467. 
[11]. Angima S., Stott D., O’Neill M., Ong C. and Weesies G., "Soil erosion prediction using RUSLE for central Kenyan highland conditions. Agriculture", Ecosystems \& Environment, 97(1), 2003, pp. 295-308.

[12]. Wischmeier W. and Smith D., "Predicting rainfall erosion losses. United States Department of Agriculture (USDA)", Agricultural Handbook No. 537. Washington DC: USDA, 1978.

[13]. Zhou Q. and Liu X.-J., "Digital Terrain Analysis. Beijing", Science Press, 2000. (in Chinese)
[14]. McCool D., "Revised slope steepness factor for the universal soil loss equation. Transactions of the ASAE (American Society of Agricultural Engineers)", 30(5), 1987, pp. 1388-1396.

[15]. Liu B.-Y., Nearing M. and Risse L., "Slope gradienteffects on soil loss for steep slopes. Transactions of the ASAE (American Society of Agricultural Engineers)", 37(4), 1994, pp. 1835-1840.

[16]. Xiao W., Hu Z.-Q. and Gong B.-K., "Visualisation of the characteristics of Mining Subsidence with the Consideration of Topography -A Case Study in China", International Journal of Mining \& Mineral Engineering, 3(1), 2011, pp. 16-25. 